\title{
Open Globe Injury in a Tertiary Care Hospital
}

\author{
Thapa $\mathrm{BB}^{1}$, Dhami $\mathrm{DB}^{2}$, Nath $\mathrm{HK}^{3}$
}

\begin{abstract}
Introduction: Open Globe Injury (OGI) is a type of mechanical eye injury in which there is a full thickness defect of the outer fibrous coat of eye ball. The Prognosis in the eyes with OGI has improved in these days. $2.4 \%$ of blindness in Nepal was due to ocular trauma in 1981. The aim of this study was to describe epidemiological profile, clinical profile and treatment outcome in eyes with open globe injury. Methodology: It is the prospective interventional non randomized hospital based study on the patients of open globe injury presented to the Nepalgunj Medical College, Nepalgunj from April 2017 to May 2018. Visual acuity, anterior and posterior segment evaluation, site and size of wound were recorded. All the eyes were underwent primary repair surgery. Postoperative visual acuity, anterior and posterior segment evaluation was carried out on all follow up. Second surgery was done if required. Results: $0.4 \%$ of ophthalmic and $\mathbf{0 . 0 1 6 \%}$ of all hospital patients had open globe injury. Most of the victims were young males. The mean age of study population was $10.98 \pm 17.1$ year. Playing (62.5\%) was the most common time of injury and wooden stick (50\%) was most common agent of injury. Zone I involvement (87.5\%) and penetrating type (91.7\%) was found in most of cases. $87.5 \%$ of eyes were blind, $4.2 \%$ were visually impaired and $8.3 \%$ had normal vision at the time of presentation. $79.2 \%$ of eye were improved after treatment on visual function, $12.5 \%$ remained unchanged while $8.3 \%$ deteriorates and leads to pthysis bulbi. Conclusion: The incidence of open globe injury was $0.4 \%$ among ophthalmic patients and $0.016 \%$ among all patients of Nepalgunj Medical College Teaching Hospital, Nepalgunj. Early Primary repair, use of systemic antibiotics and postoperative care provides encouraging anatomical and functional outcome in these eyes with OGI.
\end{abstract}

Key words: Blindness, open globe injury, primary repair

\section{INTRODUCTION}

A national survey on blindness carried in 1981 found $2.4 \%$ of blindness in Nepal is due to ocular trauma. Ocular trauma affect mostly young male. Mechanical eye injuries are classified into close globe and open globe type. In an open-globe injury (OGI) there is a full-thickness wound of the outer fibrous coat, regardless of the presence or absence of uveal or retinal involvement ${ }^{2}$. OGI is the leading cause of severe anatomical and functional destruction of the visual system.

Although severe ocular injuries comprise a small percentage of all ocular trauma cases, they are by far the most costly, to the individual and their family, the health system and to society ${ }^{1-3}$. $0.26 \%$ of pediatric eye patient at western Terai region of Nepal present with $\mathrm{OGI}^{4}$. Fong et al(1995), demonstrated $2 \%$ of all ocular injuries as open globe injuries (OGIs) ${ }^{3}$. Kinderan et al ${ }^{5}$ showed $5.3 \%$ of all eye injuries as OGI at Western Hilly region of Nepal. Dulal et al $^{6}$ detected $5.8 \%$ of all ocular injury as OGI and $0.46 \%$ of all eye patient as OGI at Midwestern Hilly region of Nepal. Inspite of considerable effort to prevent OGI related

1. Dr. Bikram Bahadur Thapa

2. Dr. Dabal Bahadur Thapa

3. Dr. Har Karan Nath

Address for correspondence:

Dr. Bikram Bahadur Thapa

Department of Ophthalmology

Nepalgunj Medical College and Teaching Hospital,

Nepalgunj, Banke, Nepal

Email:drbbthapa@gmail.com blindness, it remains common around the world, with an annual global incidence rate of 3.5/100,000 persons ${ }^{7}$.

In the present days, the prognosis of patients with OGIs has significantly improved due to use of microsurgical techniques and instrumentation as well as improved knowledge of pathophysiologic mechanism ${ }^{8}$. Poor prognostic factors for openglobe injuries are Wounds larger than $5 \mathrm{~mm}$, late presentation (after 24 hour of injury), a poor visual acuity (VA) at the first visit, a ruptured globe, zone III injuries, history of penetrating keratoplasty $(P K)$, retinal detachment (RD), vitreous haemorrhage $(\mathrm{VH})$, and expulsion of the crystalline lens ${ }^{9}$. In Midwestern and Far western region of Nepal OGI is still blinding disease in children due to lack of anesthesiologist in the eye hospitals of this region, unawareness and poverty. There is lack of study on this disease at Midwestern and Far western Nepal; thus we studied the epidemiology, clinical profile and outcome of treatment on this disease from April 2017 to May 2018 at Nepalgunj Medical College, Nepalgunj.

\section{MATERIAL AND METHODS}

Ethical approval was obtained for the study from the institutional review committee (IRC) of the Nepalgunj Medical College, Nepal. A prospective non randomized interventional study was conducted. All the patients presenting to the Nepalgunj medical college, Nepalgunj with a diagnosis of an OGI from 1st April 2017 to 31st May 2018 were included in the study. An OGI was defined as a full thickness wound of the eye wall (cornea and/or sclera) ${ }^{2}$. 
Demographic data included patient age, sex, date of injury, race, cause; nature and agent of injury were noted. Time interval between the injury and presentation was also noted. Presenting complaint, use of alcohol or recreational drugs at the time of the trauma and previous ocular surgery were recorded. The size, location and details of injuries were collected. Best-corrected visual acuity (BCVA) was recorded before and after treatment. All injuries were classified according to the Birmingham Eye Trauma Terminology (BETT) system ${ }^{2}$.

All the patients were undergone primary repair surgery under general anesthesia by a single surgeon, where he uses non absorbable 10-0 nylon suture (aurolon, Aurolab, Madurai, India) for corneal repair and absorbable 6-0 vicryl (polycryl, Aurolab, Madurai, India) for scleral and limbal repair in interrupted fashion. If iris prolapsed was non-viable, it was excised. If vitreous is prolapsed it was removed by open sky vitrectomy. All patients were admitted in the ward and 5 day course of intra venous fluoroquinolone antibiotics were given. Topical antibiotics, steroid and cycloplegics were prescribed. Patients were evaluated for visual acuity, intraocular pressure and wound integrity, sign of infection, development of any complications and need of further interventions on the day of discharge, 2 weeks after surgery, 1 month and 3 months after surgery.

Statistical analyses were performed using SPSS software. A Student's paired t-test was used to compare the quantitative variables, while the chi-square test was used to compare the categorical data. Values of $p<0.05$ were considered statistically significant.

\section{RESULTS}

Out of 5989 ophthalmic patients $0.4 \%(n=24)$ presented with open globe injury. $19(79 \%)$ of them were male and $5(21 \%)$ were female. Thus male female ratio was 3.8:1. The mean age of study population was 10.98 \pm 17.1 year (range=1-58 year). Age wise distribution is shown below in table I.

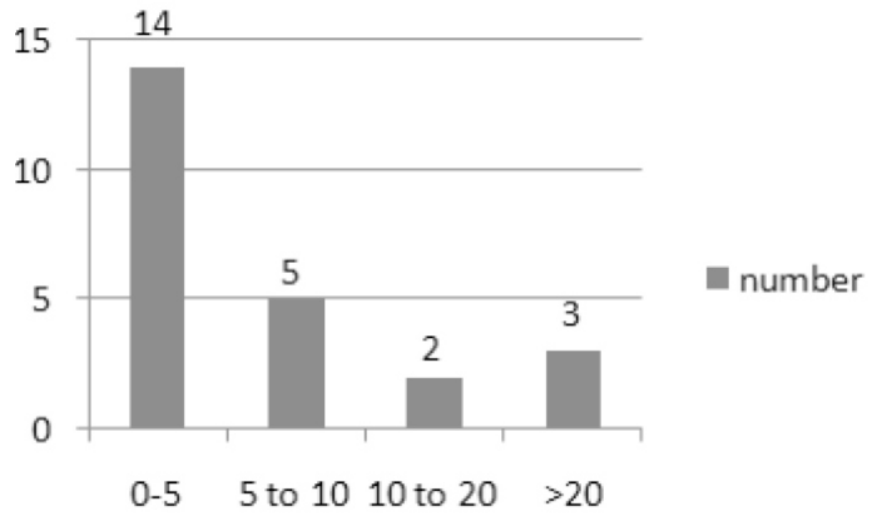

\begin{tabular}{|c|c|c|}
\hline Age group(year) & Number & Percent \\
\hline $0-5$ & 14 & 58.3 \\
\hline $5-10$ & 5 & 20.8 \\
\hline $10-20$ & 2 & 8.3 \\
\hline$>20$ & 3 & 12.5 \\
\hline
\end{tabular}

Table I: Age wise distribution

Most of our patients were from Sudurpaschim province and Kailali district as shown in table II and table III. Almost $75 \%$ of cases were referred from eye hospitals and only $25 \%$ were primary cases. Only one case (4.2\%) reached to the hospital with in 24 hour of trauma while 3 cases (12.6\%) presented only after a week.

\begin{tabular}{|c|c|c|}
\hline Province & Frequency & Percent \\
\hline Sudurpaschim & 15 & 62.5 \\
\hline No. 5 & 7 & 29.2 \\
\hline Karnali & 2 & 8.3 \\
\hline Total & 24 & 100.0 \\
\hline
\end{tabular}

Table II: Province wise distribution

\begin{tabular}{|l|c|c|}
\hline District & Frequency & Percent \\
\hline Achham & 1 & 4.2 \\
\hline Bajhang & 2 & 8.3 \\
\hline Banke & 4 & 16.7 \\
\hline Bardiya & 3 & 12.5 \\
\hline Dadeldhura & 2 & 8.3 \\
\hline Dailekh & 1 & 4.2 \\
\hline Kailali & 7 & 29.2 \\
\hline Kanchanpur & 3 & 12.5 \\
\hline Surkhet & 1 & 4.2 \\
\hline Total & 24 & 100.0 \\
\hline
\end{tabular}

Table III: District wise distribution

Most of our patients belong to Chhetri caste comprising $45.8 \%$, followed by Madheshi $16.7 \%$. While other patients belong to the Tharu, Brahmin, Magar and Dalit caste as shown in table IV.

\begin{tabular}{|l|c|c|}
\hline Caste & Frequency & Percent \\
\hline Chhetri & 11 & $45.8 \%$ \\
\hline Madheshi & 4 & $16.7 \%$ \\
\hline Tharu & 3 & $12.5 \%$ \\
\hline Brahmin & 3 & $12.5 \%$ \\
\hline Magar & 2 & $8.3 \%$ \\
\hline Dalit & 1 & $4.2 \%$ \\
\hline
\end{tabular}

Table IV: Caste wise distribution 
OGI mostly affect left eye $(p=0.011)$ in this study. Mostly OGI occurred while playing (62.5\%); followed by working, writing and road traffic accident. Most frequent injurious agent in this study was wooden stick (50\%) followed by knife, pencil, broom, broken glass and scissor etc. most of the eyes with OGI (66.7\%) has purely Zone I disease whereas $16.7 \%$ has zone I+II, $8.3 \%$ has zone II+III, $4.2 \%$ has purely zone II and $4.2 \%$ has zone I+II+III disease with lid laceration as well. The occurrence of Zone I disease is significantly higher than other $(p=0.0001)$ as shown in table $5.91 .7 \%$ of OGI were of penetrating type of which $12.5 \%$ has retained intraocular foreign body, where as $8.3 \%$ were globe rupture. Thus penetrating type is significantly frequent type of OGI ( $p=0.0001)$ as shown in table VI. Most of the eyes presented with Grade IV injury (83.3) with the visual acuity of HM to PL, only two cases with grade I while one with grade II and one with grade $\mathrm{V}$. Thus most of the OGI cases were legally blind at the presentation $(p=0.0001)$ as shown in table VII.

\begin{tabular}{|c|c|c|c|c|}
\hline ZONE & Frequency & Percent & $\begin{array}{c}\text { Valid } \\
\text { Percent }\end{array}$ & $\begin{array}{c}\text { Cumulative } \\
\text { Percent }\end{array}$ \\
\hline I & 16 & 66.7 & 66.7 & 66.7 \\
\hline I+II & 4 & 16.7 & 16.7 & 83.3 \\
\hline I+II+III + LL & 1 & 4.2 & 4.2 & 87.5 \\
\hline II & 1 & 4.2 & 4.2 & 91.7 \\
\hline II+III & 2 & 8.3 & 8.3 & 100.0 \\
\hline Total & 24 & 100.0 & 100.0 & \\
\hline
\end{tabular}

Table V: Zone wise distribution of injury

\begin{tabular}{|c|c|c|c|c|}
\hline & Frequency & Percent & $\begin{array}{c}\text { Valid } \\
\text { Percent }\end{array}$ & $\begin{array}{c}\text { Cumulative } \\
\text { Percent }\end{array}$ \\
\hline A & 2 & 8.3 & 8.3 & 8.3 \\
\hline B & 19 & 79.2 & 79.2 & 87.5 \\
\hline B+C & 3 & 12.5 & 12.5 & 100.0 \\
\hline Total & 24 & 100.0 & 100.0 & \\
\hline
\end{tabular}

Table VI: Type wise distribution of injury

\begin{tabular}{|c|c|c|c|c|}
\hline & Frequency & Percent & $\begin{array}{c}\text { Valid } \\
\text { Percent }\end{array}$ & $\begin{array}{c}\text { Cumulative } \\
\text { Percent }\end{array}$ \\
\hline I & 2 & 8.3 & 8.3 & 8.3 \\
\hline II & 1 & 4.2 & 4.2 & 12.5 \\
\hline IV & 20 & 83.3 & 83.3 & 95.8 \\
\hline V & 1 & 4.2 & 4.2 & 100.0 \\
\hline Total & 24 & 100.0 & 100.0 & \\
\hline
\end{tabular}

Table VII: Grade wise distribution of injury
All the cases need surgical intervention. All were of accidental in nature. After surgical repair, on Ultrasonography Brightness scan two cases showed dense vitreous hemorrhage and retinal Detachment whereas one case showed features of traumatic endophthalmitis and were referred for vitreoretinal care. $8(33.3 \%)$ cases underwent cataract surgery. Anatomical success was achieved in 22 eyes $(91.7 \%)$ whereas 2 eyes $(8.3 \%)$ developed pthysis bulbi. Visual function was improved in 19 eyes $(79.2 \%)$, not changed in 3 eyes $(12.5 \%)$ and deteriorate in 2 eyes $(8.3 \%)$ as depicted in table VIII.

\begin{tabular}{|c|c|c|c|c|}
\hline $\begin{array}{c}\text { Visual } \\
\text { Function }\end{array}$ & Frequency & Percent & Valid & $\begin{array}{c}\text { Cumulative } \\
\text { Percent }\end{array}$ \\
\hline Improved & 19 & 79.2 & 79.2 & 79.2 \\
\hline Deteriorate & 2 & 8.3 & 8.3 & 87.5 \\
\hline Stationery & 3 & 12.5 & 12.5 & 100.0 \\
\hline Total & 24 & 100.0 & 100.0 & \\
\hline
\end{tabular}

Table VIII: Visual function

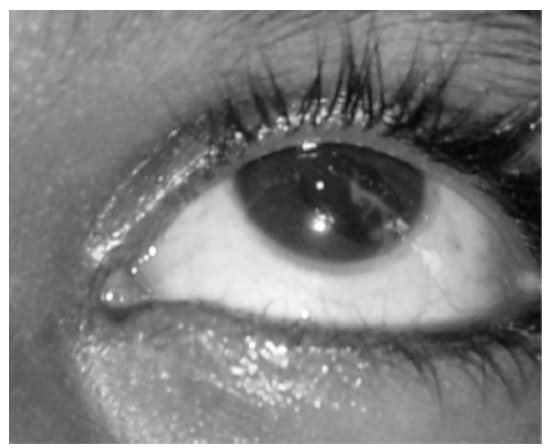

Figure 1: Child with corneal scar after primary repair of corneal laceration

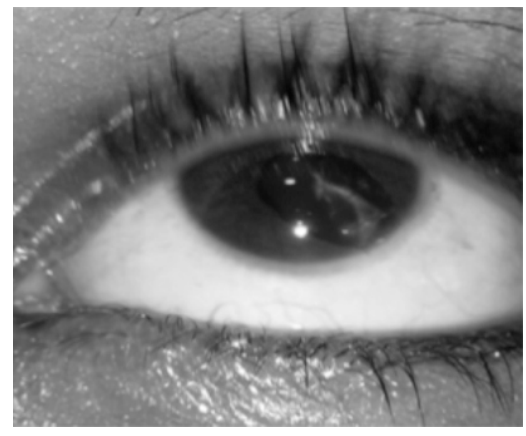

Figure 2: Eye with OGI after primary repair with suture in place and large pupil due to excision of non-viable prolapsed iris

\section{DISCUSSION}

This study evaluated the demographical and clinical profile as well as visual and anatomical outcomes after open-globe injury in patients of Midwestern and Farwestern Nepal. 0.4\% $(n=24)$ of ophthalmic patient were presented with open globe injury at Nepalgunj Medical College, Nepalgunj. The hospital incidence was $0.016 \%$ in a Multispeciality Medical College. 
The mean age of our study populations was $10.98 \pm 17.1$ year. These victims were younger than those that have been reported in other studies ${ }^{9 \cdot 12}$. Inter-population differences in the culture, lifestyle, mean lifespan, occupation, and socioeconomic status may be the causes of this variability. Another reason may be the unavailability of anesthesiology service in the eye hospitals of this region. Male: female ratio was 3.8:1. Male predominance was shown by most of other studies as well ${ }^{4,9-12}$. The cause may be male spend more time at outdoors, have risky behavior and are aggressive by nature. Most of our patients were resident of Sudurpaschim Province $(62.5 \%)$ although the hospital is located in the province no.5. The reason may be this is the nearest referral hospital of Sudurpaschim province and province no. 5 has 4 other centers to serve patients of $\mathrm{OGI}$. Again another reason may be poverty and less caring of child by parent in the Sudurpaschim province.

Chhetries were affected mostly (45.8\%) by tribe. The reason could be it is the most populated tribe in this region, their more aggressiveness and risk taking behavior. They are also involved in handling weapon as well as in war. Playing was the most common setting of injury (62.5\%) as shown by Bhattarai et al ${ }^{4}$ whereas workplace was shown by other studies ${ }^{9-12}$. The reason may be our most of patient were children as in the study of Bhattarai et $\mathrm{al}^{4}$ wooden stick was the most frequent $(50 \%)$ injurious agent in this study similar to the finding of Bhattarai et $\mathrm{al}^{4}$ but Yalcin Tok et $\mathrm{al}^{12}$ showed metal as frequent injurious agent. Left eye involvement was significantly higher than right eye in this study $(p=0.011)$ which is against the finding of earlier study where both eyes were equally affected ${ }^{9,12}$. This finding might be as a result of most of us are right handed and during playing child face each other, where left eye of victim comes in front of right hand of another child. We didn't encounter any case with bilateral OGI.

In our study $66.7 \%$ of cases were purely Zone I (i.e. cornea only) disease. Other studies showed lesser percentage of pure zone I disease than present study, despite of being most common type in all studies ${ }^{9,11,12}$. Surprisingly only one case (4.2\%) was detected with pure Zone II disease in our study, which was found in more than $1 / 3^{\text {rd }}$ of cases in earlier studies ${ }^{9-12}$. We did not found pure Zone II disease in our study. More than one zone involvement was found in $29.1 \%$ of our cases in this study; which represents more severe form of OGls. One case of blast injury has all zone involvement and both lid laceration. Penetrating type is significantly more frequent type of OGI in our study $(P=0.0001)$. Out of them $12.5 \%$ had retained intraocular foreign body. $8.3 \%$ of our study cases present with traumatic rupture of eye ball. The reason of this might be trivial mode of injury along with use of small wooden stick and sharp weapon as injuries agent. 83.3\% of eyes in this study present with grade IV injury with visual acuity of hand movement (HM) or perception of light (PL). And $4.2 \%$ present with grade $V$ injury i.e. VA of no perception of light (NPL).Thus most of eyes with OGI were legally blind at the time of presentation $(p=0.0001)$. This finding is similar to that shown by Bhattarai et al ${ }^{4}$.
And Fujikawa et al. ${ }^{9}$ In this study only $4.2 \%$ eye were present with visual acuity of No perception of light in contrast to this Fujikawa et al ${ }^{9}$ had $15 \%$ and Han et al ${ }^{11}$ had $13.5 \%$ of eyes with No Perception of Light(NPL) at presentation, whereas Bhattarai et al didn't have any eye with NPL at presentation. The reason to this may be most of our patient presented with injury during playing. After surgical treatment, visual acuity improved in $79.2 \%$ of cases which is comparable to the study of Han et a ${ }^{11}$, but higher than study by Bhattarai et al. ${ }^{4}$ Such a good functional outcome was due to early surgical repair, use of intra-venous antibiotics and frequent follow up care. Still $12.5 \%$ of cases became pthysis bulbi (anatomical failure) in this study which is comparable to the findings of Bhattarai et al ${ }^{4}$.

\section{CONCLUSION}

Open globe injury (OGI) is the most severe mechanical ocular trauma affecting $0.4 \%$ of all ophthalmic patients and $0.016 \%$ of all hospital patients. Male Childs of Chhetri tribe are at significantly higher risk of getting injured. Early surgical repair with fine microsurgical instrumentation, use of systemic antibiotics and good postoperative care provide fruitful functional and anatomical outcome in most of the eye with minimizing incidence of sympathetic ophthalmia. Knowing the circumstances of injury, we will be able to formulate preventive measures and there implementation on the society of this blinding injury.

\section{REFERENCES}

1. National survey on blindness and eye disease on Nepal by H M G, W H O / P B L, 1981 . A v a i l a b I e o n www.who.int/ncd/vision2020_action plan/documents.

2. Kuhn F, Morris R, Witherspoon C.D., Mester V. The Birmingham Eye Trauma Terminology system (BETT). J Fr. Ophtalmol., 2004; 27, 2, 206-210.

3. Fong LP. Eye injuries in Victoria, Australia. Med J Aust 1995;162(2):64-8.

4. Bhattarai B, Pokharel S, Thapa B, Gautam P, Gurung G.profile of open globe injury in children at Lumbini Eye institute. JUCMS 2015;3,9:37-40.

5. Kinderan YV et al. Ocular trauma in western region of Nepal. Nepal J Ophthalmol 2012; 4(7):5-9.

6. Dulal $S$ et al. Profile of ocular trauma in mid western region. Nepal J Ophthalmol 2012; 4(7):134-137.

7. Negrel AD, Thylefors B. The global impact of eye injuries. Ophthalmic Epidemiol. 1998;5(3):143-69.

8. Oniyke L.O. Eye injuries in children. The Nigerian J surg research 2001;3:3-4.

9. Fujikawa $\mathrm{A}$, Mohamed $\mathrm{YH}$, Kinoshita Het al. Visual outcomes and prognostic factors in open-globe injuries. BMC Ophthalmology (2018) 18:138 https://doi.org/10.1186/s12886-018-0804-4.AA.

10. Beshay N, Keay L, Dunn H et al. The epidemiology of Open Globe Injuries presenting to a tertiary referral eye hospital in Australia. Injury, Int. J. Care Injured 48 (2017) 1348-1354.

11. Han SB, Yu HG. Visual outcome after open globe injury and its predictive factors in Korea. J Trauma. 2010;69(5):E66-72.

12. Yalcin Tok O, Tok L, Eraslan E, Ozkaya D, Ornek F, Bardak Y. Prognostic factors influencing final visual acuity in open globe injuries. J Trauma.2011;71(6):1794-800. 